Original Research Article

\title{
The ABC and VED analysis of the medical store of the tertiary care teaching hospital in Maharashtra, India
}

\author{
Sujata Dudhgaonkar, Sachin R. Choudhari*, Narendra P. Bachewar
}

Department of Pharmacology, Shri Vasantrao Naik

Government Medical College, Yavatmal, Maharashtra, India

Received: 20 June 2017 Accepted: 24 July 2017

\section{*Correspondence to:}

Dr. Sachin R. Choudhari,

Email: sachinchoudhari06@ gmail.com

Copyright: (C) the author(s), publisher and licensee Medip Academy. This is an openaccess article distributed under the terms of the Creative Commons Attribution NonCommercial License, which permits unrestricted noncommercial use, distribution, and reproduction in any medium, provided the original work is properly cited.

\begin{abstract}
Background: Substantial amount of money need to be spent on medicines. The ABC-VED matrix is an attempt to evolve on proper inventory control systems. Methods: The study was conducted at medical store of tertiary care hospital in FY 2016-2017. The annual drug consumption and expenditure incurred on each medicine were collected. The data were subjected to ABC and VED analysis. For a management purpose ABC-VED matrix was formulated by combining results of both the analysis.

Results: Total 124 drugs consumed budget of INR 2,03,24,881. In the ABC analysis, Category A, B and C were consisted of 18 (14.51\%), $21(16.94 \%)$ and $85(68.55 \%)$ medicines respectively. Whereas in the VED analysis, $67(54.03 \%)$ medicines were belongs to category V [INR 1, 61, 13, 992 (79.28\%)], 38 $(30.65 \%)$ medicines to Category E [INR 35, 26,095 (17.35\%)] and $19(15.32 \%)$ medicines to Category D [INR 6, 84,794 (3.37\%)]. The ABC-VED Matrix shows that category I, II and III contained 69,38 and 17 medicines respectively. The ADE for Category I was INR 1,71,80,643 (84.53\%), for category II was INR 27, $29,919(13.43 \%)$ and for a category III medicines was INR 4, 14,319 (2.04\%). According to matrix, category I require topmost management control. Middle and lower managerial staff may supervise category II and category III respectively. Conclusions: ABC-VED analysis helps us to know about the medicines which require more stringent monitoring and management, to narrow down on fewer medicines.
\end{abstract}

Keywords: $\mathrm{ABC}, \mathrm{ABC}-\mathrm{VED}$ matrix, Annual drug expenditure (ADE), Inventory control, VED

\section{INTRODUCTION}

In a government hospital on an average about one third of its annual budget is spent on buying medicines and medical related items. ${ }^{1}$ The pharmacy is the place where, a big amount of money is spent to purchase medicines. This emphasizes the need of planning for the efficient clinical and medical services. ${ }^{2}$ The goal being to maintain adequate stock of all required essential medicine to provide interrupted medical services to the population.

A study conducted by the Department of Personnel and Administrative Reforms in India has revealed that not only does the quantity of medicines received fall short of the requirement but also the supply is often erratic. Even common medicines are out of stock and remain so for a considerable period. ${ }^{3}$ A study from a 1,500-bedded statefunded hospital has claimed that, there was approximately $20 \%$ savings on expensive drugs by control measures. ${ }^{4}$ Role of inventory control is very important in a developing country like India. ${ }^{5}$ Inventory control system helps us to know what, when and how much to order, and how much to stock depending upon purchasing costs and storing costs. It also helps to maintain balance in terms of supply and demand. ${ }^{5}$ 
Monitoring of each and every drug is impossible in the health system. So, it is important to look for the costliest medicines first, which consume the major part of the budget, and then to make a strategy for further study and identify their use pattern. Two factors are important for the effective drug management, cost and criticality of the item. Of all available inventory control systems, the $\mathrm{ABC}$ (always better control) and VED (vital, essential and desirable) matrix is an important and most preferred tool. ${ }^{5-7}$

ABC analysis is "Always Better Control" analysis based on Pareto's principle of "Vital few and trivial many" depending on capital investment of the items. ${ }^{8}$ According to it, drugs are classified into three categories:

- Category A: First 10-15\% of the items account for approximately $70 \%$ of budget,

- Category B: $20-25 \%$ items that account for a further $20 \%$ of the total budget

- Category C: Remaining 65-70\% items, amounting for $10 \%$ of the total budget. ${ }^{5-9}$

$\mathrm{ABC}$ analysis is based only on monetary value and the rate of consumption of the item. A low monetary value item may have vital role and their consumption may be life saving. So, their importance cannot be neglected just because they didn't belong to category A drug. ${ }^{10,11}$

VED analysis is based on need of the items at the hospitals. According to it, items are classified into three categories: vital, essential and desirable. Vital includes the items without which hospital services and patient care seriously hampered. Essential includes those without which hospital services cannot run beyond a week and patient care adversely affected. Desirable include items without which patient care would not adversely affect. ${ }^{5,10,12}$

A combination of $\mathrm{ABC}$ and VED analysis (ABC-VED matrix) gives more meaningful information regarding inventory. A vital and expensive item comes under category I (AV, BV, CV, AE, and AD). Remaining items of the $\mathrm{E}$ and $\mathrm{B}$ groups comes under category II (BE, CE, BD). Category III includes the cheaper and desirable items (CD). ${ }^{12}$

This hospital is a tertiary care centre in central India. Recently there is constant increase in numbers of patients. To satisfy the healthcare needs of rising number of patient it is necessary to use the resources wisely. Strict inventory control over drug items should be there in order to maintain adequate stock of the required drug items so that the supply of essential items goes uninterrupted. Hence this study was planned.

The aim of present study was:

- To analyze annual consumption of medicine and expenditure incurred in FY 2016-17.
- $\quad$ To do ABC, VED and ABC-VED matrix analysis of medicines.

- To identify the items which require more stringent supervision and monitoring.

\section{METHODS}

The study was conducted at medical store department of tertiary care hospital in Vidarbh region of Maharashtra of central India during the period from 01.04.2016 to 31.03.2017. Permission was taken from the Head of the institute and in charge medical store prior to the study. Confidentiality of data was maintained throughout the study. Considering the objectives of the study, the ethical clearance was waived off.

The data on annual drug consumption of each drug and expenditure incurred on each item of the drug store for the financial year 2016-17 were collected. The data were filled into an MS Excel spreadsheet. All the values were mentioned as percentage. The statistical analysis was done with the help of MS Excel statistical functions.

All the drugs purchased were subjected to $A B C$ analysis. In $\mathrm{ABC}$ analysis the annual expenditure of each drug was calculated by multiplying the unit cost with annual consumption. The annual drug expenditure (ADE), values were arranged in descending order of INR. The cumulative cost was calculated. The percentage of budget spent on each medicine was calculated. Accordingly, medicines purchased were divided into three groups: Group A, B and $\mathrm{C}$ category wherein Group A consumed nearly $70 \%$ of the total budget, group B consumed $20 \%$ of total expenses, while group $\mathrm{C}$ consumed $10 \%$ of $\mathrm{ADE}$. The final values vary marginally.

Further the drugs were subjected to VED analysis, wherein the drugs were classified into vital, essential and desirable category based on criticality. VED status of medicines was decided by consulting the in charge medical store and physicians. Vital drugs (V) included critical life saving drugs that must be available round the clock, the drugs without which hospital services and patient care gets seriously hampered. Essential drugs (E), drugs of relatively lower criticality the included absence of which may be tolerated for a short while i.e. this includes those drugs without which hospital services cannot run beyond a week and patient care adversely affected. Remaining drugs were included under desirable D group the availability of which will not paralyse the hospital care significantly. $^{12}$

Further for a management purpose ABC-VED matrix was formulated by combining results of $\mathrm{ABC}$ and $\mathrm{VED}$ analysis. Nine subgroups were formed i.e. AV, AE, AD, $\mathrm{BV}, \mathrm{BE}, \mathrm{BD}, \mathrm{CV}, \mathrm{CE}$ and $\mathrm{CD}$. Where first letter stand for its (medicine) position in $\mathrm{ABC}$ analysis and second letter stands for its position in VED analysis. Thus, out of nine subgroups three categories were formed, viz. Category 1 included high priority drugs, requiring more attention AV, 
AE, AD, BV and CV. Category 2 included drugs needing relatively low management $\mathrm{BE}, \mathrm{CE}$ and $\mathrm{BD}$, whereas items from $C D$ group included in category 3 drugs of low priority management. According to matrix Category 1 and Category 2 medicines required high management priority and direct supervisory monitoring.

\section{RESULTS}

On hospital list, there were total 124 medicines. The total annual drug expenditure (ADE) for these medicines during the FY 2016-17 was INR 2,03,24,881 which was about $2.1 \%$ of total annual expenditure of hospital. Total 124 drugs were used with an annual expenditure of INR 2, 03, 24,881 which include cost of indoor and outpatient dispensing.

Out of 124 drugs, Category A, B and C were consisted of 18 (14.51\%), $21(16.94 \%)$ and $85(68.55 \%)$ medicines respectively. The ADE for category A was INR 1,41,74,704 (69.75\%), for Category B was INR 41,14,698 (20.24\%) and for Category C was INR 20,35,479 (10.01\%) (Table 1). The cut-off values were not exactly at $70 / 20 / 10 \%$, and differed marginally, which is permissible. ${ }^{13}$ The results are shown graphically for better understanding (Figure 1).

Table 1: The ABC, VED and ABC-VED matrix analysis of SVNGMC pharmacy (2016-17).

\begin{tabular}{|lllll|} 
Category & $\begin{array}{l}\text { No. of } \\
\text { medicines }\end{array}$ & $\begin{array}{l}\% \text { of } \\
\text { medicines }\end{array}$ & $\begin{array}{l}\text { ADE } \\
\text { (INR) }\end{array}$ & $\begin{array}{l}\% \text { of } \\
\text { ADE }\end{array}$ \\
\hline A & 18 & 14.51 & 14174704 & 69.75 \\
\hline B & 21 & 16.94 & 4114698 & 20.24 \\
\hline C & 85 & 68.55 & 2035479 & 10.01 \\
\hline V & 67 & 54.03 & 16113992 & 79.28 \\
\hline E & 38 & 30.65 & 3526095 & 17.35 \\
\hline D & 19 & 15.32 & 684794 & 3.37 \\
\hline I & 69 & 55.65 & 17180643 & 84.53 \\
\hline II & 38 & 30.65 & 2729919 & 13.43 \\
\hline III & 17 & 13.70 & 414319 & 2.04 \\
\hline
\end{tabular}

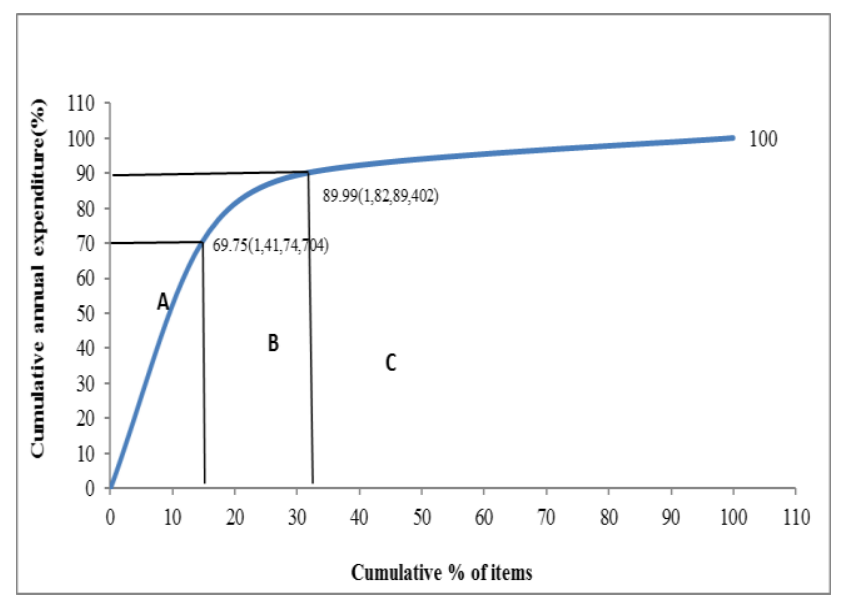

Figure 1: ABC analysis cumulative curve (2016-17).
These 124 drugs were subsequently undergone VED analysis. Table 1 and Figure 2 showed the results of VED analysis. About 67 (54.03\%) items were belongs category $\mathrm{V}$ and ADE for the same was INR 1, 61, 13,992 (79.28\%). Category E and Category D was consisted of 38 (30.65\%) and $19(15.32 \%)$ medicines respectively. Annual drug expenditure for Category E was INR 35, 26,095 (17.35\%) and that of Category D was INR 6, 84,794 (3.37\%). For any drug inventory $\mathrm{ABC}$ analysis of drug items alone is not enough as this will overlook the desired managerial control of vital medicine over B and $\mathrm{C}$. Whereas when only VED is considered for managerial control strategy purpose some D category drugs will be included in the priority list which will hamper management. Therefore ABC-VED matrix model is decided to overcome this prioritisation in managerial control mechanism. Particularly while deciding on rationalising on repeated order placement and effective vigilance.

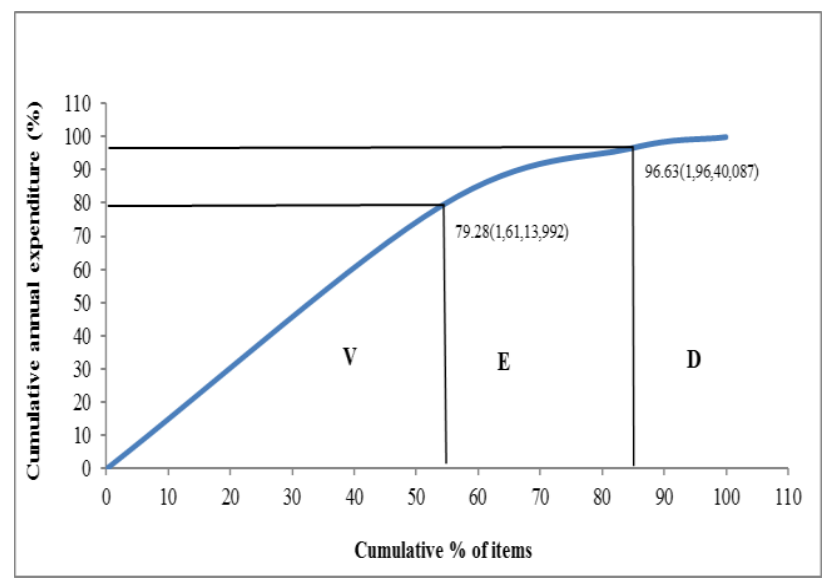

Figure 2: VED analysis cumulative curve (2016-17).

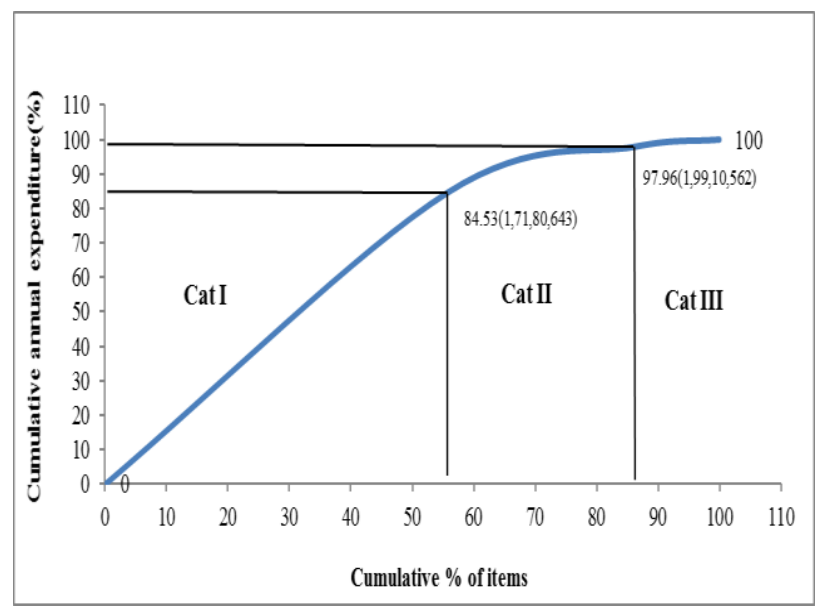

Figure 3: ABC-VED matrix cumulative curve (2016-17).

Based on ABC-VED matrix analysis, Table 2 and Table 4 shows the results of matrix analysis. Total nine different subcategories (AV, AE, AD, BV, BE, BD, CV, CE and $\mathrm{CD})$ were analysed using this matrix. Among these nine subgroups three categories were formed category 1,2 and 
3 (Table 1). There were about $69(55.65 \%)$ medicines in category 1 . About $38(30.65 \%)$ and $17(13.70 \%)$ medicines were belonging to category 2 and 3 respectively. The ADE for Category 1 was INR 1,71,80,643 (84.53\%), category 2 was INR 27, 29,919(13.43\%) and a category 3 medicine was INR 4, 14,319 (2.04\%) (Table 1, Figure 3).

Table 2: ABC-VED matrix analysis of the SVNGMC pharmacy (2016-17).

\begin{tabular}{|c|c|c|c|c|c|c|}
\hline & \multicolumn{2}{|l|}{$\mathbf{V}$} & \multicolumn{2}{|l|}{$\mathbf{E}$} & \multicolumn{2}{|l|}{ D } \\
\hline & $\begin{array}{l}\text { No. of } \\
\text { medicines (\%) }\end{array}$ & $\begin{array}{l}\text { ADE } \\
\text { (INR) (\%) }\end{array}$ & $\begin{array}{l}\text { No. of } \\
\text { medicines (\%) }\end{array}$ & $\begin{array}{l}\text { ADE } \\
\text { (INR) (\%) }\end{array}$ & $\begin{array}{l}\text { No. of medicines } \\
(\%)\end{array}$ & $\begin{array}{l}\text { ADE } \\
\text { (INR) }(\%)\end{array}$ \\
\hline A & $16(12.90)$ & $\begin{array}{l}13108053 \\
(64.49)\end{array}$ & $02(01.61)$ & $\begin{array}{l}1066651 \\
(05.25)\end{array}$ & $00(00)$ & $00(00)$ \\
\hline B & $10(08.06)$ & $1990123(09.79)$ & 09 (07.26) & $\begin{array}{l}1854100 \\
(09.12)\end{array}$ & $02(1.61)$ & $270475(01.33)$ \\
\hline $\mathrm{C}$ & $41(33.06)$ & $1015816(05.00)$ & $27(21.77)$ & $605344(02.98)$ & $17(13.71)$ & $414319(02.04)$ \\
\hline Total & 67 (54.02) & $\begin{array}{l}16113992 \\
(79.28)\end{array}$ & $38(30.64)$ & $\begin{array}{l}3526095 \\
(17.35)\end{array}$ & $19(15.32)$ & $684794(03.37)$ \\
\hline
\end{tabular}

The Matrix shows that category I (69 medicines) require topmost management control that would help in keeping check on available budget and drug availability. Middle and lower managerial staff may supervise category II (38 medicines) and category III (17 medicines) respectively.

\section{DISCUSSION}

In the tertiary care hospital facility, availability of services including medicines was crucial factor for the provision of health care. Besides criticality, cost of the items was equally important. The present study attempted to identify medicine needing intense management using ABC-VED matrix. This study found that about $70 \%$ of ADE spending occurred on only $10-15 \%$ of drug items. This figure is lower than similar study conducted by Devnani $\mathrm{M}$ et al, and Wandalkar et al, at PGIMER, Chandigarh and B J Medical College, Pune respectively. ${ }^{14,15}$ This group require more stringent monitoring as it consumes major part of annual drug expenditure for fewer medicines. We also found that not all drugs from this category were vital. Few essential medicines were also included in this category.
ABC-VED matrix analysis helps us to know about the medicines which require strict monitoring.

Present study showed that ABC analysis alone, would help to keep control over $18(14.51 \%)$ medicines from category A which is lower than findings of Devnani et al, of PGIMER, Chandigarh and Wandalkar et al, of B J Medical College, Pune but was comparable to the study of Anand et al, undertaken in medical college at New Delhi which consumes almost $70 \%$ of ADE. ${ }^{14-16}$ At the same time 51 (41.12\%) vital drugs from category B and C would be compromised. Table 3 depict the results of similar studies in India.

Similarly, if only VED is considered then ideal control can be exercised only on vital and essentials. Here in this study, $67(54.03 \%)$ medicines, $38(30.65 \%)$ medicines and $19(15.32 \%)$ medicines included in category V, category E and category D respectively. However, Sushil Kumar Maj in his study showed that medicines included in vital, essential and desirable category were 201 (13.14\%), 866 $(56.37 \%)$ and $469(30.49 \%)$ respectively. ${ }^{17}$

Table 3: Comparison of ABC, VED and ABC-VED matrix analysis of different studies in India.

\begin{tabular}{|lllllll|l|}
\hline Category & $\begin{array}{l}\text { Present } \\
\text { study }\end{array}$ & $\begin{array}{l}\text { Mahatme et } \\
\mathbf{a l}^{\mathbf{1 1}}\end{array}$ & $\begin{array}{l}\text { PGI Chandigarh } \\
\text { Study }\end{array}$ & $\begin{array}{l}\text { Wandalkar } \\
\text { et al }\end{array}$ & $\begin{array}{l}\text { Anand } \\
\text { et al }^{\mathbf{1 6}}\end{array}$ & $\begin{array}{l}\text { GMCH, Nagpur } \\
\text { study }^{\mathbf{1 8}}\end{array}$ & $\begin{array}{l}\text { AFMC } \\
\text { study }^{\mathbf{1 9}}\end{array}$ \\
\hline A & 14.51 & 14.50 & 13.78 & 13.40 & 18.60 & 10.76 & 14.46 \\
\hline B & 16.94 & 18.20 & 21.85 & 16.50 & 24.00 & 20.63 & 22.46 \\
\hline C & 68.55 & 67.30 & 64.37 & 70.10 & 57.40 & 68.61 & 63.08 \\
\hline V & 54.03 & 24.20 & 12.11 & 50.90 & 13.20 & 23.76 & 07.39 \\
\hline E & 30.65 & 68.50 & 59.38 & 40.20 & 38.80 & 38.12 & 49.23 \\
\hline D & 15.32 & 07.30 & 28.51 & 08.90 & 48.00 & 38.12 & 43.38 \\
\hline I & 55.65 & 31.50 & 22.09 & 57 & 28.70 & 29.15 & 20.92 \\
\hline II & 30.65 & 68.50 & 54.63 & 35 & 41.10 & 41.26 & 48.92 \\
\hline III & 13.70 & 00 & 23.28 & 8 & 30.20 & 29.59 & 30.16 \\
\hline
\end{tabular}

Note: All figures are in percentage $(\%)$ 
In our study, VED analysis helps to keep control over vital and/or essential medicines which accounting for about $96 \%$ of annual drug expenditure. However, category A contains 2 essential and category B contains 10 vitals and 2 desirable drug items. This list would be always overlapping and different since list of vital, essential and desirable medicines will be varied hospital to hospital depending on level of healthcare and type of medical care being provided. The comparative data of similar studies in India showed in the Table 3 . It showed the wide variation among the drug items in the category V, E and D. Such consequences can be avoided by doing ABC-VED matrix analysis.

Table 4: ABC and VED matrix analysis during the year 2016-17.

\begin{tabular}{|llll|}
\hline Category & Subgroups & $\begin{array}{l}\text { Total no. } \\
\text { of drugs } \\
(\%)\end{array}$ & $\begin{array}{l}\text { Cost } \\
\text { INR } \\
(\mathrm{ADE}) \\
(\%)\end{array}$ \\
\hline $\begin{array}{l}\text { Category } \\
\text { I }\end{array}$ & $\begin{array}{l}\text { AV+AE+AD+BV+CV } \\
(16+02+00+10+41)\end{array}$ & $69(55.65)$ & $\begin{array}{l}17180643 \\
(84.53)\end{array}$ \\
\hline $\begin{array}{l}\text { Category } \\
\text { II }\end{array}$ & $\begin{array}{l}\text { BE+BD+CE } \\
(09+02+27)\end{array}$ & $38(30.65)$ & $\begin{array}{l}2729919 \\
(13.43)\end{array}$ \\
\hline $\begin{array}{l}\text { Category } \\
\text { III }\end{array}$ & $\begin{array}{l}\text { CD } \\
(17)\end{array}$ & $17(13.70)$ & $\begin{array}{l}414319 \\
(02.04)\end{array}$ \\
\hline Total & & $124(100)$ & $\begin{array}{l}20324881 \\
(100)\end{array}$ \\
\hline
\end{tabular}

\section{ABC VED matrix analysis}

In our study, ABC-VED matrix showed Category 1, Category 2 and category 3 comprise of 69 (55.65\%), 38 $(30.65 \%)$ and $17(13.70 \%)$ medicines respectively. While Anand et al showed 37 (28.68\%), 53 (41.09\%) and 39 $(30.23 \%)$ medicines included in category 1,2 and 3 respectively. ${ }^{15}$ Analysis of $\mathrm{ABC}-\mathrm{VED}$ matrix helps us to concentrate on $69(55.65 \%)$ medicines which belong to category I for strict monitoring as these items are vital, essential and/or expensive. For About 1, 71, 80,643 $(84.53 \%)$ of $\mathrm{ADE}$ was spend on these items. More specifically medicines belonging to subcategories AV, BV and AE of this category I which accounts for nearly 28 $(22.57 \%)$ medicines and 1,61,64,827 (79.53\%) of ADE were quite expensive. Control and management of category 1 (vital) would help in keeping check on annual budget and availability of medicines. Hence, constant effort should be made to bring down number of AD items which usually take away a good chunk of budget. Also, their non availability is not going to make much difference in quality health care. In this study, we found $00(00 \%)$ drug items in subcategory $\mathrm{AD}$, which is a sign of good inventory control.

Stock of category I medicines need to be maintained round the year for smooth functioning of hospital as their unavailability will always be unacceptable. To prevent unavailability it is necessary to keep low cost buffer stock always available while keeping close vigilance on the consumption and stock in hand. A two bin method can also help to reduce risk of shortage of these medicines. In this study, we found that subcategory CV of Category I contains $41(33.06 \%)$ medicines which are much higher in number than the other similar studies done by Devnani et al, and Anand et al. ${ }^{14,16}$ At the same time it consumes only $5 \%(10,15,16)$ of total $\mathrm{ADE}$ which is quite low as compared to other subcategories. Hence, stock of these medicines need to be maintained as per need since many vital drugs are included in this subcategory.

Stock of these medicines need to be maintained throughout the period for smooth functioning of hospital as their unavailability is unacceptable. To prevent this, it is necessary to keep low cost buffer stock always available while keeping close vigilance on the consumption and stock in hand. A two-bin method can also help to reduce risk of shortage of these drug items. In our study we found subcategory CV from Category I contained 41 (33.06\%) medicines which are much higher than the other similar studies done by Anand et al and Devnani et al. ${ }^{13,15}$ At the same time it costs only $5 \%$ of total ADE which is quite low as compared to other subcategories. So, Stock of these items need to be maintained as per need since many vital drug also included in this subcategory.

In our study, Category II contains 38 (30.65\%) medicines, costing around $13.43 \%(27,29,919)$ of ADE. This category contains few essential drugs. These drugs can be ordered only once or twice a year depending upon their demand and/or need. This will cut extra money to be spent on ordering and handling of these items. At the same time sufficient stock can be maintained. Management of the category 2 medicines helps in providing all essential drugs to be available all time.

In our Category III, $17(13.71 \%)$ medicines consume nearly $2.04 \%$ of total ADE. Mainly desirable drugs belong to this category. This category considered as low priority in management consume only $2 \%$ of annual budget, does not include any vital and essentials can be managing by lower level personnel. These medicines can be ordered only if there is need. even if they consume very less amount of total ADE still we can save that money and can be utilise to buy vital or essential drug items. Similar results of other studies in India is shown in the Table 3. ${ }^{11,14-}$ $16,18,19$

\section{CONCLUSION}

In medical store Dept. of SVNGMC, Yavatmal INR 2, 03, 24,881 money was spent to purchase 124 drug items during the period of 2016-17. Considering the fact that this is a tertiary hospital, major part of ADE was used to purchase vital and essential drug items. Although amount used was quite high as compared to other studies, strict vigilance was required to keep it around $70 \%$. Hence, the inventory management tool is must for effective control on drug store. The medicine need to be placed according to available stock and need of drugs. An inventory tool helps 
to manage all this. Close eye has to be kept on purchase of expensive, vital and essential drugs. ABC-VED analysis helps us to know about the medicines which require more stringent monitoring and management. Also, it cuts extra money to be spent on purchase of medicines which are less needed. Ultimately, it helps to better use of available resources and budget and also to avoid out of stock situation at the drug store without compromising patient health care. In all to conclude, inventory control technique need to be followed routinely in this institution which will improve patient care with optimal and judicious use of resources.

\section{ACKNOWLEDGEMENTS}

Authors would like to thank the staff of medical store for cooperation throughout the study. Authors are also thankful to our Dean for permitting access to store records.

Funding: No funding sources

Conflict of interest: None declared

Ethical approval: The study was approved by the Institutional Ethics Committee

\section{REFERENCES}

1. Kant S, Pandaw CS, Nath LM. A management technique for effective management of medical store in hospitals. Medical store management technique. Journal [Academy of Hospital Administration (India)]. 1996;8(2-1):41-7.

2. Kunders GD, Gopinath S, Katakam A. Planning and designing supportive services-Pharmacy. In: Hospitals: Planning, Design and Management. New Delhi: Tata McGraw-Hill Publishing Company Limited; 2000:273-281.

3. Kidwai M. Inaugural address. Logistics and supply management for health and family planning programme: A report of inter-country course. New Delhi: National Institute of Health and Family Welfare; 1992:66-70.

4. Pillans PI, Conry I, Gie BE. Drug cost containment at a large teaching hospital. Pharmacoeconomics. 1992;1:377-82.

5. Gupta S, Kant S. Inventory control. In: Hospital stores management - An integral approach. New Delhi: Jaypee Brothers Medical Publishers(P) Ltd; 2000:6072.

6. Jha SM. Management of Hospital Materials and Stores, Hospital Management: Himalaya Publishing House; 2001:229.

7. Ramanathan R. ABC inventory classification with multiple-criteria using weighted linear optimization. Comput Oper Res. 2006;33:695-700.

8. Hartman MG. Separate the vital few from the trivial many. Quality Progress. 2001 Sep 1;34(9):120.

9. Doshi RP, Patel N, Jani N, Basu M, Mathew S. ABC and VED analyses of drug management in a government tertiary care hospital in Kerala. iHEA 2007, $6^{\text {th }}$ World Congress: Explorations in Health Economics Paper; 2007. Available at: http://www.ssrn.com/abstract=992566 [last accessed on 2009 Aug 14]

10. Das JK. Inventory Control. In: Kaushik M, Agarwal AK, Arora SB, editors. Essentials of Logistics and Equipment Managemnt, Manual of Post Graduate Diploma in Hospital and Health Management. New Delhi: Indira Gandhi National Open University, School of Health Sciences; 2001.

11. Mahatme MS, Hiware SK, Shinde AT, Salve AM, Dakhale GN. Medical store management: An integrated economic analysis of a Tertiary Care Hospital in Central India. Journal of Young Pharmacists. 2012 Apr 1;4(2):114-8.

12. Vaz FS, Ferreira AM, Kulkarni MS, Motghare DD, Pereira-Antao I. A Study of Drug Expenditure at a Tertiary Care Hospital: An ABC-VED Analysis. J Health Manag. 2008;10:119-27.

13. Ammer DS. Materials management and purchasing. Bombay: D.B. Taraporevala Sons and Co. Pvt. Ltd; 1982.

14. Devnani M, Gupta A, Nigah R. ABC and VED analysis of the pharmacy Store of a tertiary care teaching, research and referral healthcare institute Of India. J Young Pharm. 2010;2:201-5.

15. Wandalkar P, Pandit PT, Zite AR. ABC and VED analysis of the drug store of a tertiary care teaching hospital. Indian Journal of Basic and Applied Medical Research. 2013;3(1):126-31.

16. Anand T, Ingle GK, Kishore J, Kumar R. ABC-VED analysis of a drug store in the Department of Community Medicine of a Medical College in Delhi. Indian journal of pharmaceutical sciences. 2013 Jan;75(1):113.

17. Kumar S, Chakravarty A. ABC-VED analysis of expendable medical stores at a tertiary care hospital. Medical journal armed forces India. 2015 Jan 31;71(1):24-7.

18. Thawani V, Turankar A, Sontakke S, Pimpalkhute S, Dakhale G, Jaiswal K, et al. Economic analysis of drug expenditure in Government Medical College hospital, Nagpur. Indian journal of pharmacology. 2004 Jan 1;36(1):15.

19. Gupta R, Gupta KK, Jain BR, Garg RK. ABC and VED analysis in medical stores inventory control. Med J Armed Forces India. 2007;63:325-7.

Cite this article as: Dudhgaonkar S, Choudhari SR, Bachewar NP. The ABC and VED analysis of the medical store of the tertiary care teaching hospital in Maharashtra, India. Int J Basic Clin Pharmacol 2017;6:2183-8. 